\title{
Spatial Temporal Dynamics and Risk Zonation of Dengue Fever, Dengue Hemorrhagic Fever, and Dengue Shock Syndrome in Thailand
}

\author{
Phaisarn Jeefoo \\ Geographic Information Science Field of Study, School of Information and Communication Technology, \\ University of Phayao, 19 Moo 2, Mae-Ka, Mueang, Phayao 56000 Thailand \\ Email: phaisarn.je@up.ac.th / p.jeefoo@gmail.com
}

\begin{abstract}
This study employed geographic information systems (GIS) to analyze the spatial factors related to dengue fever (DF), dengue hemorrhagic fever (DHF), and dengue shock syndrome (DSS) epidemics. Chachoengsao province, Thailand, was chosen as the study area. This study examines the diffusion pattern of disease. Clinical data including gender and age of patients with disease were analyzed. The hotspot zonation of disease was carried out during the outbreaks for years 2001 and 2007 by using local spatial autocorrelation statistics (LSAS) and kernel-density estimation (KDE) methods. The mean center locations and movement patterns of the disease were found. A risk zone map was generated for the incidence. Data for spatio-temporal analysis and risk zonation of DF/DHF/DSS were employed for years 2000 to 2007. Results found that the age distribution of the cases was different from the general population's age distribution. Taking into account that the quite high incidence of DF/DHF/DSS cases was in the age group of 13-24 years old and the percentage rate of incidence was $42.9 \%$, a DF/DHF/DSS virus transmission out of village is suspected. An epidemic period of 20 weeks, starting on 1st May and ending on 31st September, was analyzed. Approximately $25 \%$ of the cases occurred between Weeks 6-8. A pattern was found using mean centers of the data in critical months, especially during rainy season. Finally, it can be identified that from the total number of villages affected (821), the highest risk zone covered 7 villages $(0.85 \%)$; the moderate risk zone comprised 39 villages $(4.75 \%)$; for the low risk zone 22 villages $(2.68 \%)$ were found; the very low risk zone consisted of 120 villages $(14.62 \%)$; and no case occurred in 633 villages $(77.10 \%)$. The zones most at risk were shown in districts Mueang Chachoengsao, Bang Pakong, and Phanom Sarakham. This research presents useful information relating to the DF/DHF/DSS. To analyze the dynamic pattern of DF/DHF/DSS outbreaks, all cases were positioned in space and time by addressing the respective villages. Not only is it applicable in an epidemic, but this methodology is general and can be applied in other application fields such as dengue outbreak or other diseases during natural disasters.
\end{abstract}

Index Terms - Geographic Information System (GIS), Dengue Fever (DF), Dengue Hemorrhagic Fever (DHF), Dengue Shock Syndrome (DSS), Local Spatial Autocorrelation Statistics (LSAS), Kernel-density estimation (KDE)

\section{INTRODUCTION}

Dengue fever (DF), and its more severe forms, dengue hemorrhagic fever (DHF) and dengue shock syndrome (DSS), is the most important arthropod-transmitted viral disease affecting humans in the world today [1]. The objective of this study was to analyze the epidemic outbreak patterns of DF/DHF/DSS in Chachoengsao province, central part of Thailand, in terms of geospatial distribution and risk area identification. The methodology and the results could be useful for public health officers to develop a system to monitor and prevent DF/DHF/DSS outbreaks.

Vector borne diseases are the most common worldwide health hazard and represent a constant and serious risk to a large part of the world's population [2]. Among these diseases, dengue fever, especially known in Southern Asia, is sweeping the world, hitting countries with tropical and warm climates. It is transmitted to humans by the mosquito of the genus Aedes and exists in two forms: the Dengue Fever (DF) or classic dengue and the Dengue Hemorrhagic Fever (DHF), which may evolve into a severe form known as Dengue Shock Syndrome (DSS) [3]. There are four dengue virus serotypes, called DEN-1, DEN-2, DEN-3, and DEN-4. They belong to the genus Flavivirus, family Flaviviridae [4]. The global prevalence of dengue diseases has grown dramatically in recent decades. The disease occurs in over 100 countries and territories and threatens the health of more than 2.5 billion people in urban, periurban, and rural areas of the tropics and subtropics. The major disease burden is in Southern Asia and the Western Pacific [5]. Rapid expansion of urbanization, inadequate piped water supplies, increased movement of human populations within and between countries, and future development and spread of insecticide resistance in the mosquito 
vector populations are some of the reasons for the increase of dengue transmission in recent years [6]. Today, in several Asian countries, dengue incidence is a leading cause of pediatric hospitalization and death [7].

In Thailand there has been an upward trend in the incidence of dengue, and acute and severe forms of dengue virus infection, since the first dengue epidemic outbreak in 1958 [8]. In 2011, according to the dengue surveillance data, the total number of reported cases of dengue infections in Thailand is 37,728 cases with 27 deaths nationwide. The number of reported dengue cases in Chachoengsao province in this same period is a total of 1020 cases and no deaths (Ministry of Public Health, Thailand).

Geographic Information System (GIS) technologies have long been extensively applied in public health studies and related issues like disease outbreak during natural disasters, at the regional or country level, to assess and identify potential risk factors involved in DF/DHF/DSS incidence transmission such as socioeconomic, climatic, demographic and physicalenvironment variables to better understand essential characteristics of predicted risk areas [9,10]. Previous researchers such as Rotela et al., (2007) found the spacetime analysis of the dengue spreading dynamics in the 2004 Tartagal outbreak, Northern Argentina. The results showed that the age distribution of the cases was different from the population age distribution, and the cases showed outbreak spotlights and spreading patterns that could be related to entomologic and epidemiologic factors [11]. GIS have proved great potentialities in addressing epidemiological problems [12]. The use of spatial analysis tools is important to identify critical control areas with several variables intimately related to the modulation of the disease dynamics [13]. A GIS is a valuable tool for investigating whether seropositivity for dengue is clustered [7]. Yost (2006) applied the model to GIS data or new sites to forecast probability of occurrence for unsampled areas within the spatial extent of sampling [14]. He demonstrates that using census data and statistical analysis coupled with GIS analysis can provide useful information for land management decision-making [15].

A GIS is agnostic to this distribution and handles spatial features without regard to the underlying statistical model. Without proper caution, it is therefore possible for the unwary user to apply totally inappropriate techniques to spatial objects (such as a point or polygon) contained in a GIS. Points, in particular, require special attention, since a point could be a sample location from a random surface (geostatistical analysis), or the location of a random event (point pattern analysis) [16]. In spatial analysis such as kernel-density estimation (KDE), spatial autocorrelation analysis (SAA), hotspot, or mean center, temporal dynamics are commonly used to symbolize spatial patterns of diseases and to test whether there is a considerable occurrence of clustering of disease incidences in a particular area [17-21]. Previous research has used human cases in GIS by geocoding addresses to describe their distribution [20,22]. At the same time, kernel density functions were performed on dead crow data to document geographic density of the cases. Maps of human cases and cluster analysis were used to show the grouping of cases that were validated using virus positive mosquito sample sites in those same areas [20,23]. Research done by Brownstein et al., (2002) showed how GIS can be used in the spatial analysis of human infections when mosquito, human, and dead bird clusters were reported to estimate the risk of disease in a population [23]. Kernel-density estimation (KDE) represents a very popular subject of statisticians' investigations [24]. The kernel is based on the value of the standard deviation in the Gaussian equation [14]. Wist et al., (2005) studied statistical properties of successive wave heights and successive wave periods. The histogram of the data and the kernel-density estimation of the data are compared with the Bretschneider model [25]. Spatial autocorrelation, or spatial dependence, is the characteristic that observations tend to take values that are not independent of those of neighbouring observations [26-29]. Spatial autocorrelation is a measure of the similarity of objects within an area [30]. Spatial autocorrelation is a powerful technique for the analysis of spatial patterning in variate values which has been successfully applied in locational geography $[26,31,32]$. Premo (2003) introduced two local spatial statistics that were designed to elucidate how distance-defined clusters of values, called spatial neighborhoods, contribute to the global spatial structure of a distribution. The results raise a number of local-scale hypotheses that, though undetected by previous global spatial analysis, might lead to a refined interpretation of the spatial distribution of dated monuments and, by extension, the reorganization of the Classic Maya [32]. Cai and Wang (2006) presented a method to quantify the spatial autocorrelation of topographic index (TI) in a catchment context using spatial statistical indices originating in geographic studies [33].

Local patterns of spatial autocorrelation were suggested as an appropriate perspective for understanding local instabilities and expressed as a local indicator of spatial association (LISA), local $G_{i}$ and $G_{i}^{*}$ statistics. Similar descriptions of this local autocorrelation were called "hot spot" $[16,34,35]$. The use of the Getis statistic $\left(G_{i}^{*}\right)$ provides insights on the spatial ramifications of a spatial change to model input. Specifically, the location of significant $G_{i}^{*}$ values identified areas where the differences in leaf area index (LAI) and stand volume occur and are spatially clustered [36]. Local spatial autocorrelation indices are a decomposition of the global Moran I index [37]. Although spatial autocorrelation was defined decades ago, its application has been limited by computation capacity and software availability [38-41]. Recent advances in local spatial statistics have led to a growing interest in the detection of disease clusters or "hotspot", for public health surveillance and for 
improving our understanding of the disease such dengue incidence [16,34,35,42].

In this study, spatial analyses at a provincial scale (KDE, LSAS, mean center, temporal dynamics) were used to investigate spatio-temporal diffusion patterns of DF/DHF/DSS incidence. The main objectives of this work were to find a spatio-temporal diffusion pattern and risk zonation map of $\mathrm{DF} / \mathrm{DHF} / \mathrm{DSS}$ incidence that occurred in Chachoengsao province, Thailand from 2000 until 2007 by using GIS elements for a better understanding of DF/DHF/DSS outbreak dynamics, and to correlate them to climatic and demographic factors.

\section{STUDY AREA AND METHODS}

\section{A. Study area: Chachoengsao province, Thailand}

Chachoengsao province had a morbidity rate of 39.68 per 100,000 population among provinces under the surveillance of the Ministry of Public Health of Thailand for 2007 (Table I). Chachoengsao, a province in the central part of Thailand, was selected as the study area (Figure 1). This province was selected as the study area because it has reported high incidence rates for the last several years. Chachoengsao province included 11 districts, which are Mueang Chachoengsao, Bang Khla, Bang Nam Prieo, Bang Pakong, Ban Pho, Phanom Sarakham, Sanam Chai Khet, Plaeng Yao, Ratchasan, Tha Takiap, and Khlong Khuean. The province is $80 \mathrm{~km}$ distant from the eastern part of Bangkok, and covers an area of 5,238.31 sq. $\mathrm{km}$. The province has a population of about 645,022 people (Department of Administration, 2007).

TABLE I. TOP TEN MORBIDITY RATES OF DF/DHF/DSS INCIDENCE BY PROVINCE IN YEAR 2007

\begin{tabular}{|c|l|c|}
\hline Rank & \multicolumn{1}{|c|}{ Province } & $\begin{array}{c}\text { Morbidity rate } \\
\text { (per 100,000 population) }\end{array}$ \\
\hline 1. & Ranong & 55.63 \\
\hline 2. & Chachoengsao & 39.68 \\
\hline 3. & Saraburi & 32.78 \\
\hline 4. & Phetburi & 31.78 \\
\hline 5. & Prachinburi & 30.15 \\
\hline 6. & Ratchaburi & 27.51 \\
\hline 7. & Rayong & 23.93 \\
\hline 8. & Bangkok & 23.42 \\
\hline 9. & Nakhonphatom & 23.12 \\
\hline 10. & Lopburi & 22.87 \\
\hline
\end{tabular}

Source: Ministry of Public Health, Thailand

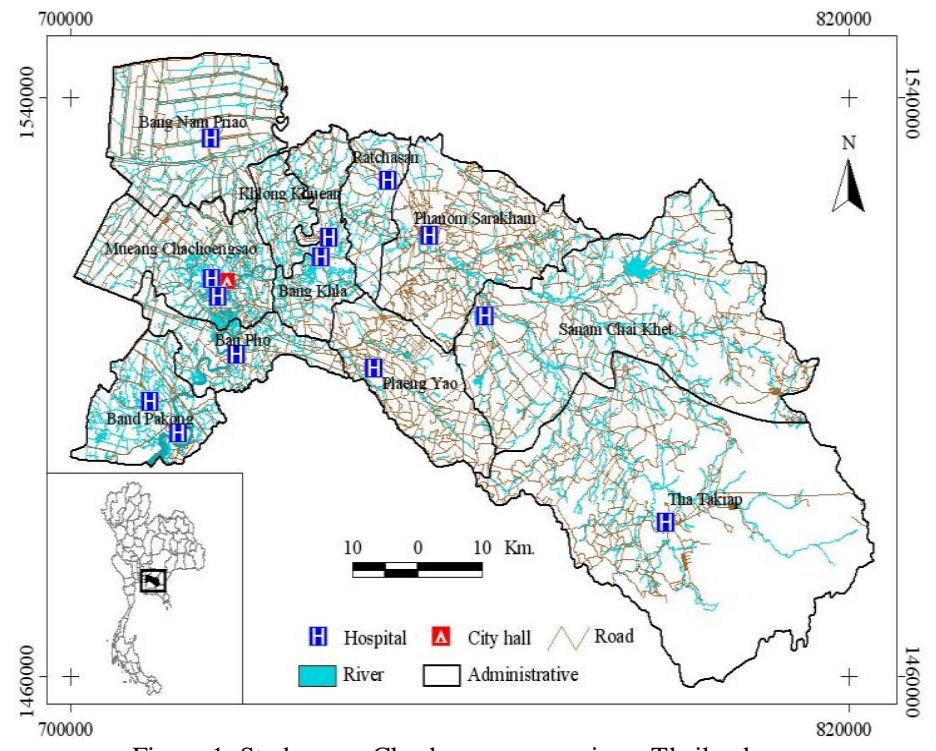

Figure 1. Study area: Chachoengsao province, Thailand

\section{B. Methods}

The flowchart summarizes the methodology of the study as shown in Figure 2. Different components of the methods are detailed below:

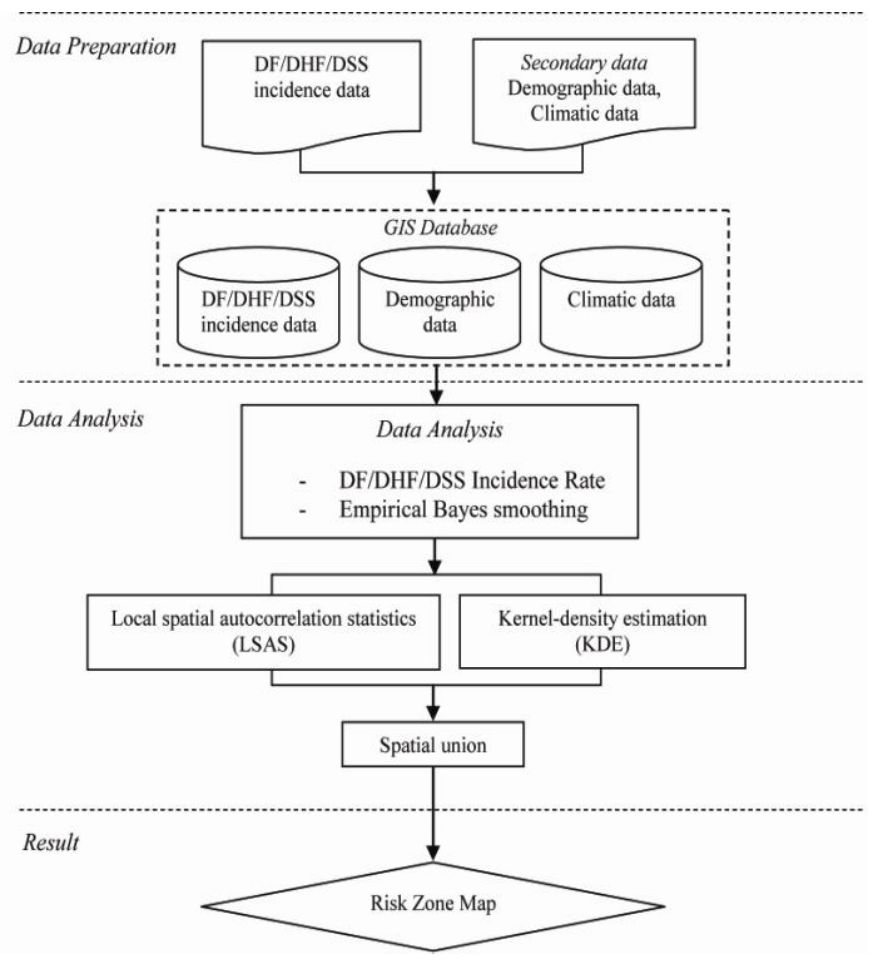

Figure 2. Methodology for mapping risk zones of DF/DHF/DSS

\section{1) Data Preparation}

The study of spatio-temporal diffusion pattern and risk zonation of DF/DHF/DSS incidence covers the 821 villages in Chachoengsao province: 


\section{a) $D F / D H F / D S S$ incidence data}

Chachoengsao province was selected for the case study because in every year, the incidence of DF/DHF/DSS has been high. DF/DHF/DSS data during years 2000 through 2007 were collected from the Chachoengsao Provincial Public Health Office, with regard to the number of reported cases per district per month, to record the probable and confirmed DF/DHF/DSS cases. Data represents only the patients who visit the hospital and fill the official Form 506 from the Bureau of Vector borne Disease, Ministry of Public Health, Thailand. The forms provided data such as the total of DF/DHF/DSS cases by month and year, type of disease, gender, and address of each patient. This data was employed for the study.

\section{b) Demographic data}

The weekly data of the DF/DHF/DSS incidences in years 2001 and 2007, as they had high numbers of DF/DHF/DSS cases, and the total number of population by each village in year 2007 were also collected from Chachoengsao Provincial Public Health Office and Department of Administration, in order to deepen the observation and support the demographic aspect analysis. Some groupings were constructed, i.e., on the basis of the population distribution, age distribution, and gender using the data for year 2007 (Table III). Also, the classification by gender is presented in Table 2. Data analysis (Table II) revealed that the worst outbreak of DF/DHF/DSS cases took place in years 2001 (1,236 cases) and in 2007 (792 cases). Accordingly, data for these years were employed to define risk zonation in Chachoengsao province.

\section{c) Climatic data}

Monthly weather data of rainfall, temperature, and humidity for the years from 2000 to 2007 were collected from the Department of Meteorology, Thailand. DF/DHF/DSS incidence outbreaks in Chachoengsao province occurred in years 2001 and 2007. The climate office has reported that that the DF/DHF/DSS incidence outbreaks coincided with El Nino years. El Nino events in Thailand are actually related to high temperature and also to low rainfall [2]. Thailand experiences rains from May to September. The remaining part of the year remains mostly dry. Besides the rainfall and temperature, humidity also influences dengue transmission [43]. Due to high humidity in rainy season, mosquito survival is longer and growth is conducive [44]. Overall, the temperature in Chachoengsao province was between 26.63 to $29.98^{\circ} \mathrm{C}$ in 8 years $(2000-2007)$. Higher than $20^{\circ} \mathrm{C}$ is the favorable temperature for Aedes Aegypti mosquitoes [45]. The average monthly humidity in 8 years (2000-2007) was found to be $72.68 \%$.

\section{2) Data Analysis}

a) Hotspot Delineation using Spatio-temporal Analysis

It was found from data analysis that the worst outbreak of suspected DF/DHF/DSS cases happened in years 2001 (1,236 cases) and 2007 (792 cases). Thus those data were applied in this study to define hotspot and risk zonation during both years. The dengue (DF/DHF/DSS) incidence rate $\left(I R_{\text {Dengue }}\right)$ is a ratio of number of observed incidence cases $\left(n_{i}\right)$ in each year divided by total population in each village $(p)$. More explicitly;

$$
I R_{\text {Dengue }}=\frac{n_{i}}{p}
$$

In addition, hotspot analysis was carried out by using the empirical Bayes smoothing method, and dengue incidence rates were used to estimate underlying risk [46] Concerning the empirical Bayes smoothing method, when raw rates are used to estimate this underlying risk, differences in population size result in variance instability and spurious outliers. So, rate smoothing is one way to address this variance instability. Essentially, rates are smoothed and thus stabilized by borrowing strength from other spatial units by using GeoDa 0.9.5i open source software $[10,16,47]$ so all DF/DHF/DSS cases data in years 2001 and 2007 in Chachoengsao province were geocoded using GeoDa 0.9.5i and a custom address locator, which included village code. The 821 village locations were geocoded and saved in dBASE format. If choosing the latter, the counts for DF/DHF/DSS cases are usually standardized and compared with total of population distribution by villages for a total of 821 villages. Although this is a very common strategy, it is not always expected that the results are dependent on the configuration of area units. As a result, it has become common recently within studies of geographical epidemiology to conduct analysis that uses the point events themselves. Based on the local spatial autocorrelation statistics (LSAS) method, the hotspot of DF/DHF/DSS incidence analysis map was generated for 2001 and 2007 years in ArcGIS 10.

So to test for statistically significant local $\mathrm{DF} / \mathrm{DHF} / \mathrm{DSS}$ clusters for each year, and to determine the spatial extent of these clusters, the Getis-Ord $G_{i}^{*}$ statistic was used [34,48,49]. The $G_{i}^{*}$ statistic is useful for identifying individual members of local clusters by determining the spatial dependence and neighboring observations [49-51]. The $G_{i}^{*}$ statistic includes the value at $i$ in the calculation of $G_{i}^{*} . G_{i}^{*}$ is calculated and then is output as the standard normal variant with an associated probability from the z-score distribution $[49,52]$. The $G_{i}^{*}$ is a group-level statistic, where point data must first be aggregated to areas. $G_{i}^{*}$ was calculated using the spatial statistics tools in the ArcGIS 10 ArcToolbox.

Using the ratio of number of DF/DHF/DSS incidences in each village during years 2001 and 2007 divided by number of the population in each village in years 2001 and 2007, it was found that as many as 352 (2001) and 254 (2007) villages affected by DF/DHF/DSS incidence location at Chachoengsao matched the criteria to be the variables.

Moreover, the hotspot by using kernel-density estimation (KDE) method was carried out for finding the 
DF/DHF/DSS incidence hotspot zonation map. Usually, the $\mathrm{KDE}$ is that the pattern has a density at any location in the study area. This density is estimated by counting the number of DF/DHF/DSS incidence cases in Chachoengsao province; centering the location where the estimate is to be made. The simplest approach, called the naive method in the literature, is to use a circle centered at the location for which a density estimate is required. $\mathrm{KDE}$ relates to location data and refers to a kernel method for obtaining a spatially smooth estimate of the local intensity of events over Chachoengsao province, which essentially amounts to a "DF/DHF/DSS risk zone" for the occurrence of those events.

DF/DHF/DSS incidence zonation maps were created using LSAS and KDE methods. The mean center or spatial mean gave the central location of disease points [53]. In this study, the UTM zone 47 North and WGS 84 coordinate system was adopted. With the coordinate system defined, the mean center can be found easily by calculating the mean of the $x$-coordinates (or Easting) and the mean of the $y$-coordinates (or Northing). These two means of the coordinates define the location of the mean center of DF/DHF/DSS incidence location as:

$$
\left(\bar{x}_{m c}, \bar{y}_{m c}\right)=\left(\frac{\sum_{i=1}^{n} x_{i}}{n}, \frac{\sum_{i=1}^{n} y_{i}}{n}\right) \text {, }
$$

Where $x_{m c}$ and $y_{m c}$ are the coordinates of DF/DHF/DSS incidence mean center, $x_{i}$ and $y_{i}$ are the coordinates of $\mathrm{DF} / \mathrm{DHF} / \mathrm{DSS}$ incidence in each point, and $n$ is the number of points [54]. The incidence risk zones map was generated based on LSAS and KDE methods by using spatial union analysis.

\section{RESUlTS AND DisCUSSION}

From documentation (Chachoengsao Provincial Public Health Office, 2007), it was found that DF/DHF/DSS occurred in the majority of the areas in Chachoengsao province; it inflicted severe health problems and financial tolls on the population affected. The worst outbreak of suspected DF/DHF/DSS cases was in year $2001(1,236$ cases) and in year 2007 (792 cases). The lowest occurrence was in year 2000 (380 cases). To widen the observation, the data collected from years 2000-2007 were classified into several groups for the ease of socioeconomic analysis, i.e. gender, area, timing, and age groups. Table II, shows that the total of cases reported was 5,565, composed of 2,989 males and 2,576 females. During the highest DF/DHF/DSS incidence in year 2001, male patients composed about 626 cases while female patients comprised only 610 cases. The ratio of male patients was higher than of female, which is $53.71 \%$.
TABLE II. THE NUMBER OF DF/DHS/DSS CASES CLASSIFIED BY GENDER GROUP FROM YEARS 2000-2007

\begin{tabular}{|c|c|c|c|}
\hline \multirow{2}{*}{ Year } & \multicolumn{2}{|c|}{ Gender } & \multirow{2}{*}{ Total } \\
\cline { 2 - 3 } & Male & Female & \\
\hline 2000 & 218 & 162 & 380 \\
\hline 2001 & 626 & 610 & 1,236 \\
\hline 2002 & 475 & 456 & 931 \\
\hline 2003 & 374 & 316 & 690 \\
\hline 2004 & 323 & 221 & 544 \\
\hline 2005 & 306 & 217 & 523 \\
\hline 2006 & 251 & 218 & 469 \\
\hline 2007 & 416 & 416 & 792 \\
\hline $\begin{array}{c}\text { Percentage } \\
(\%)\end{array}$ & 53.71 & 46.29 & 100.00 \\
\hline
\end{tabular}

Source: Chachoengsao Provincial Public Health Office

The climate of Thailand can be divided into three seasons: the hot season (February-May), rainy season (May-October), and cold season (October-February) respectively. Observation of the epidemiological characteristics of DF/DHF/DSS disease follows in three seasons. The distribution of DF/DHF/DSS incidence in years 2000-2007 is shown in Figure 3. Interestingly, disease patterns indicated that the critical months of incidence were during May to September, which is in the rainy season. The worst incidence noted was in July 2001 with more than 200 cases. The DF/DHF/DSS distribution in the whole province, having its highest incidence in rainy season, had a similar trend for every year. The cause of DF/DHF/DSS incidence is related to rainfall, temperature, and humidity so that DF/DHF/DSS generally occurred when the rainfall was comparatively lower and humidity was higher than average [2,55-57]. This demonstrates that rainfall, temperature, and humidity increased starting in May and after approximately 30 days or one month, the DF/DHF/DSS outbreak began. Moreover, in September, rainfall and humidity are highest.

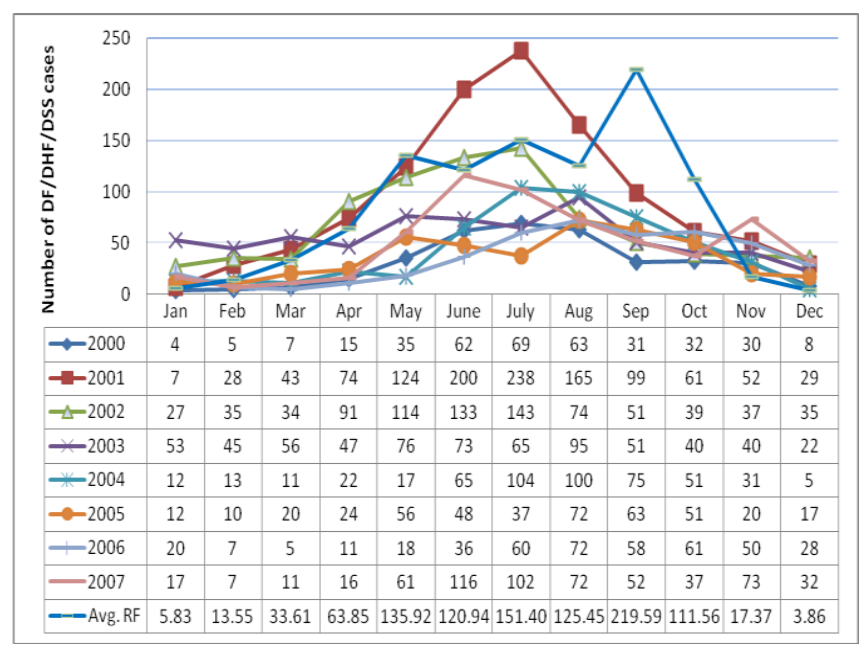

Figure 3. Number of DF/DHF/DSS cases and average rainfall on monthly basis from years 2000-2007 
The monthly data was also broken down into a more detailed investigation. During year 2007, one of the highest outbreak years, 792 patients were suspected with DF/DHF/DSS cases. At that time, the epidemic took 20 weeks or 152 days, starting on 1st May and ending in high mobility of this population group on 31st September - in other words, the rainy season period. There were as many as 521 suspected DF/DHF/DSS cases spread throughout the region and it affected $0.08 \%$ of the total population (Figure 4). Approximately $25 \%$ of the cases occurred between Weeks 6-8, with the highest number occurring in Mueang Chachoengsao district of which 178 cases were reported, and the second highest was Panom Sarakham district with 170 cases. Most cases happened in June 2007, with 171 cases, while February 2007 had the lowest rate with only 9 cases.

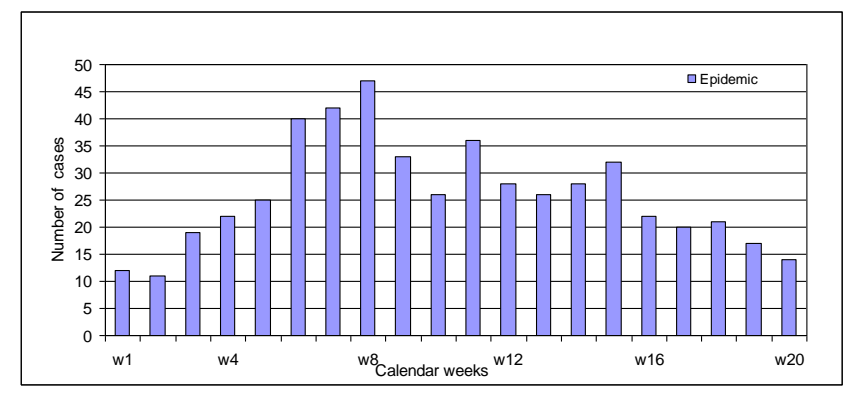

Figure 4. Number of suspected DF/DHF/DSS cases reported weekly during the 2007 epidemic (May 01-September 30)

Disease distribution based on age of the patients was also determined. The age distribution of DF/DHF/DSS cases was different from the population age distribution and the highest incidence was in the 13 to 24 year group and percentage rate of incidence was $42.9 \%$, with a lower incidence on population older than 25 years old and percentage rate of incidence was $24.3 \%$ (Table III).

TABLE III. THE NUMBER OF DF/DHF/DSS CASES BY AGE GROUP DISTRIBUTION FOR YEAR 2007

\begin{tabular}{|c|c|c|c|c|}
\hline $\begin{array}{c}\text { Age } \\
\text { group } \\
\text { (year) }\end{array}$ & $\begin{array}{c}\text { DF/DHF/ } \\
\text { DSS } \\
\text { (case) }\end{array}$ & $\begin{array}{c}\text { Total } \\
\text { population } \\
\mathbf{2 0 0 7}\end{array}$ & $\begin{array}{c}\text { Rate of } \\
\text { DF/DHF/DSS } \\
\text { Incidence } \\
(\%)\end{array}$ & $\begin{array}{c}\text { Population } \\
\text { Rate (\%) }\end{array}$ \\
\hline $0-12$ & 260 & 117,194 & 32.8 & 18.2 \\
\hline $13-24$ & 340 & 118,823 & 42.9 & 18.4 \\
\hline $25-36$ & 121 & 132,832 & 15.3 & 20.6 \\
\hline $37-48$ & 52 & 126,104 & 6.6 & 19.5 \\
\hline$>48$ & 19 & 150,069 & 2.4 & 23.3 \\
\hline Total & 792 & 645,022 & 100.0 & 100.0 \\
\hline
\end{tabular}

Source: Chachoengsao Provincial Public Health Office

All spatial statistics processing to create hotspots was carried out using the spatial statistics tools in the ArcGIS 10 ArcToolbox. The hotspot analysis was carried out using the "Hotspot Analysis (Getis-Ord $G_{i}^{*}$ )" tool in the mapping cluster tools extension. By plotting the hotspots of outbreaks in years 2001 and 2007, the zonation was found to be along the Bang Pakong River (Figure 5).
A DF/DHF/DSS incidence map was constructed from the cumulative number of cases during the entire epidemic, and confirmed that DF/DHF/DSS cases were spreading all around the province with hotspots in the Mueang Chachoengsao (2001) and Panom Sarakham (2001 and 2007), and were around the urban centers (Figure 6).

The mean center of the cases were found in critical months, especially during rainy season from May through September in years 2001 and 2007 (Figure 7). It also showed the trend diffusion cluster pattern in the center of the province at Bang Khla district.

From Figure 8, it can be concluded that movement from location 1 (May) to location 2 (June) moved to the east in 2001 but moved to the west in 2007, and changed direction to the west to location 3 (July) in 2001 but moved to the north in 2007 and moved to location 4 (August) in the north and changed direction to location 5 (September) in the west, same as year 2007. This kind of recording is necessary for agent-based models as implied in our study of pedestrian disease in space and time.
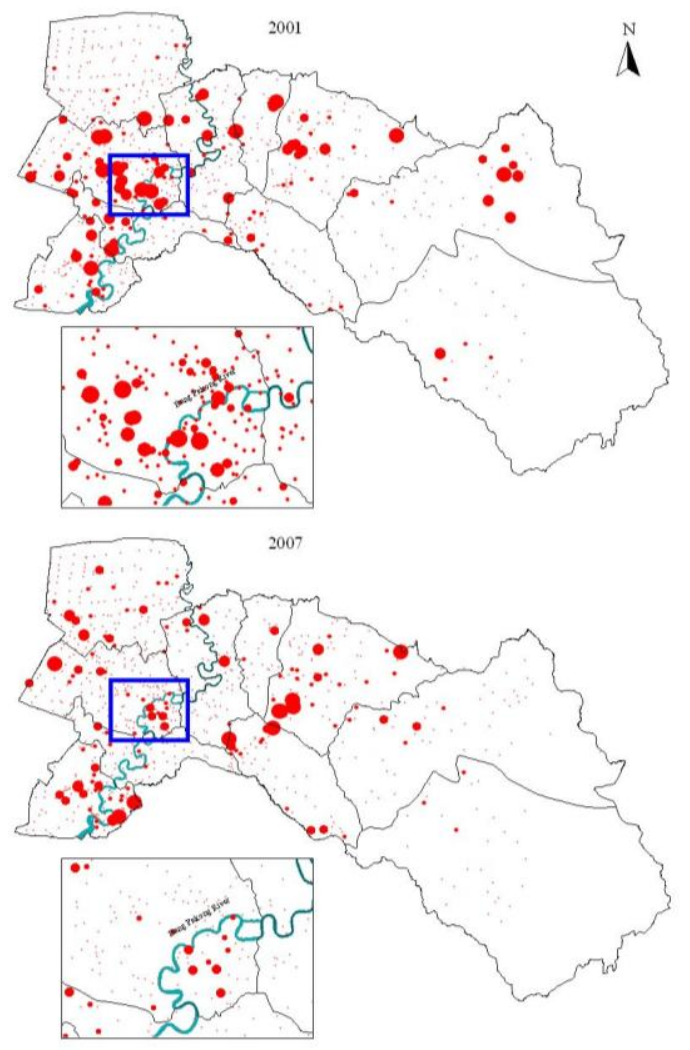

$$
\begin{array}{cl}
\text { DFDHFDSS Risk Classes } \\
>3 \text { (High) } \\
2-3 \text { (Moderate) } \\
1-2 \text { (Low) } \\
0-1 \text { (Very low) } \\
<0 \text { (No case) } \\
\quad \text { Bang Pakong River } \\
\square \text { District Boundary }
\end{array}
$$

Figure 5. Incidence maps showing the hotspot distribution of DF/DHF/DSS outbreaks during the years 2001 and 2007 using local spatial autocorrelation statistic (LSAS) method 

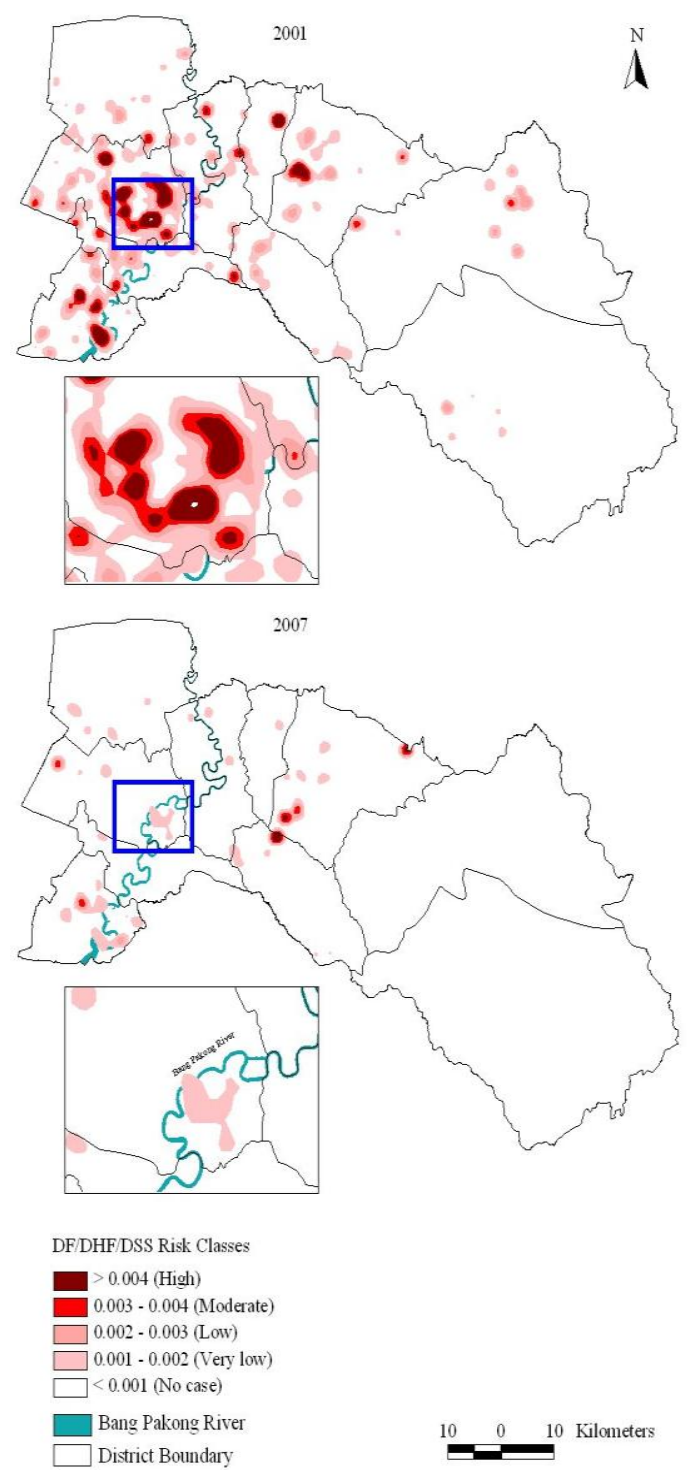

Figure 6. Incidence map showing cumulative number of DF/DHF/DSS cases in 2001 and 2007 outbreaks using kernel-density estimation (KDE) method

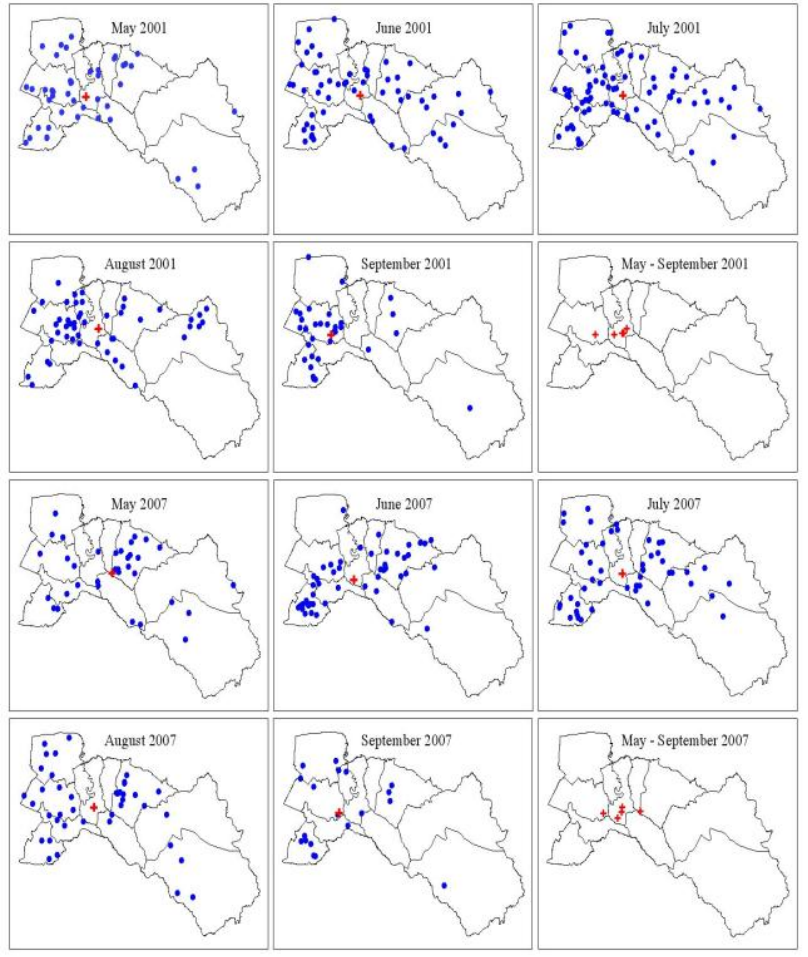

Figure 7. The mean center locations of DF/DHF/DSS outbreaks between May-September in years 2001 and 2007
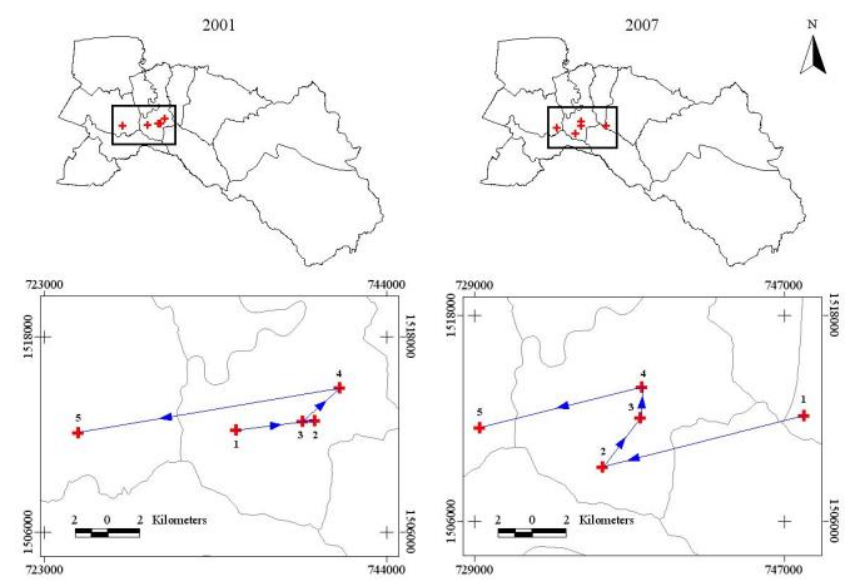

Figure 8 . Temporal dynamics in space and time. The mean center locations of DF/DHF/DSS outbreaks between May-September $(1 \rightarrow 2$

$\rightarrow 3 \rightarrow 4 \rightarrow 5$ ) in years 2001 and 2007

Lastly, Figure 9 represents the DF/DHF/DSS risk zone map in Chachoengsao province by spatial union analysis. 


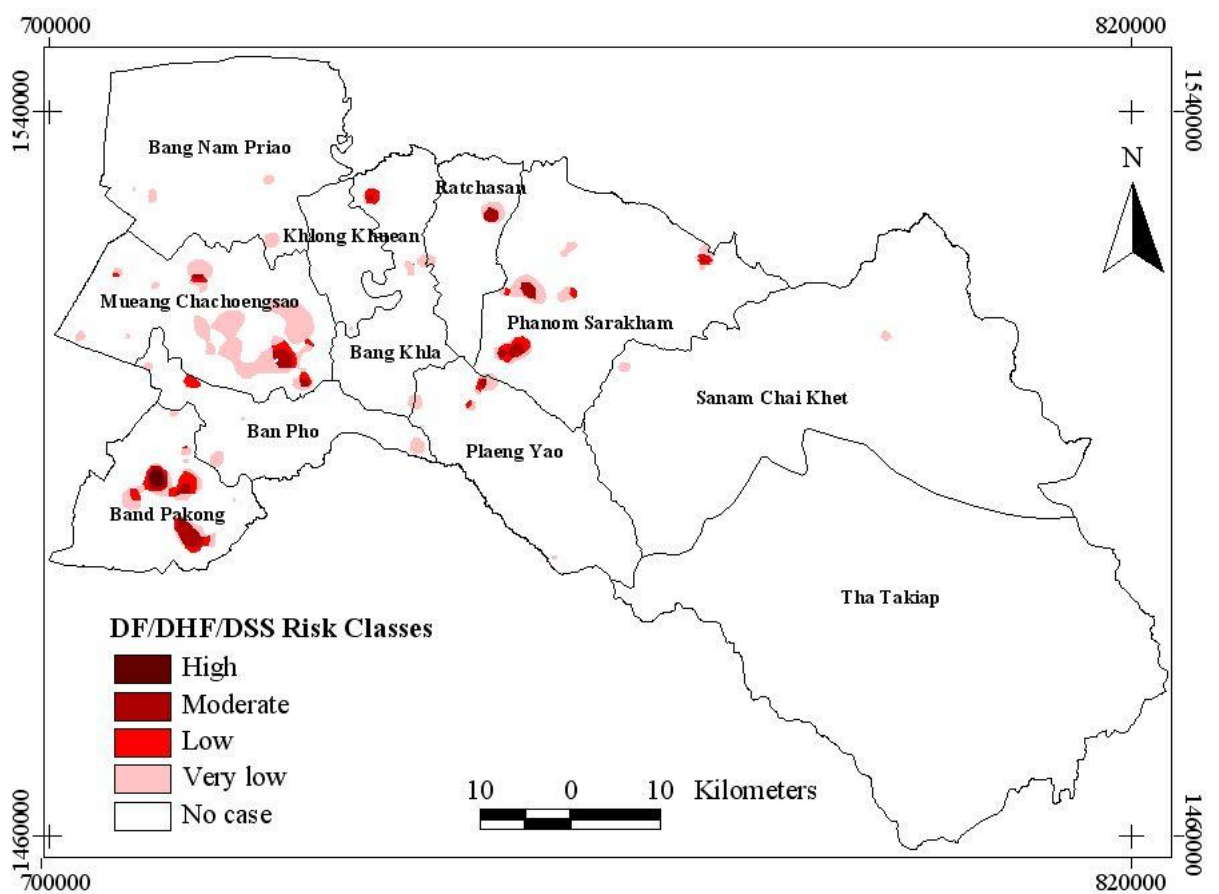

Figure 9. DF/DHF/DSS risk zone map of Chachoengsao province, Thailand

Table IV shows the summary of DF/DHF/DSS risk zones with the total number of villages (821 villages). Results indicated that the highest risk zone covered 7 villages $\left(0.85 \%, 2.45 \mathrm{~km}^{2}\right.$ of total area), the moderate risk zone comprised of 39 villages $\left(4.75 \%, 23.49 \mathrm{~km}^{2}\right.$ of total area), the low risk zone of 22 villages $\left(2.68 \%, 26.07 \mathrm{~km}^{2}\right.$ of total area) was found, the very low risk zone consisted of 120 villages $\left(14.62 \%, 111.49 \mathrm{~km}^{2}\right.$ of total area) and no case consisted 633 villages $\left(77.10 \%, 5074.81 \mathrm{~km}^{2}\right.$ of total area).

TABLE IV. SUMMARY OF VILLAGES DF/DHF/DSS AFFECTED

\begin{tabular}{|c|c|c|c|}
\hline $\begin{array}{c}\text { Risk } \\
\text { classes }\end{array}$ & $\begin{array}{c}\text { DF/DHF/DSS } \\
\text { affected }\end{array}$ & $\begin{array}{c}\text { Percentage } \\
\mathbf{( \% )}\end{array}$ & $\begin{array}{c}\text { Area } \\
\mathbf{( k m}^{2} \mathbf{)}\end{array}$ \\
\hline High & 7 & 0.85 & 2.45 \\
\hline Moderate & 39 & 4.75 & 23.49 \\
\hline Low & 22 & 2.68 & 26.07 \\
\hline Very low & 120 & 14.62 & 111.49 \\
\hline No case & 633 & 77.10 & 5074.81 \\
\hline Total & 821 & 100.00 & 5238.31 \\
\hline
\end{tabular}

\section{CONCLUSION}

Recent monitoring and planning of control measures for dengue epidemics have become a critical issue. This research offered useful information relating to the DF/DHF/DSS incidences. To analyze the dynamic pattern of the 2001 and 2007 DF/DHF/DSS outbreaks in Chachoengsao province, Thailand, all DF/DHF/DSS cases were positioned in space and time by addressing the respective villages.
This takes into account that the quite high incidence of DF/DHF/DSS cases were in the age group of 0-24 years old. It was also noted that males have a higher risk of incidence than females. Thanks to awareness amongst older people, the prior immunity to dengue in older individuals, and less mosquito biting rates in children, there are less numbers of victims in other age groups. Meanwhile, the mobility of productive aged people within "hotspot" neighborhoods has led them into the risk of getting infected with DF/DHF/DSS. Analysis of the climatic factors such as rainfall, temperature, and humidity with the dengue incidences has shown that dengue generally occurred when average temperature rose above normal, and also occurred when the humidity was higher than average and rainfall was reasonably lower. In 2007, the Chachoengsao Provincial Public Health Office reported 792 suspected DF/DHF/DSS cases and a total of $171 \mathrm{DF} / \mathrm{DHF} / \mathrm{DSS}$ cases occurred in June. During the 152 days of the epidemic, there were as many as 521 suspected DF/DHF/DSS cases spread throughout the region and affected $0.08 \%$ of the total population. Furthermore, several studies confirmed that dengue risk exposure is greater at home because of endophilic habits of Aedes Aegypti and clinical symptoms may also be less reported in young people because of better self-recovery ability [11].

Spatial autocorrelation can be a valuable tool to study how spatial patterns change over time [58]. The empirical Bayes method has the technique to improve the population density from $I R_{\text {Dengue }}$ to be empirical Bayes rate which is more accurate and useful. This theorem enables researchers to analyze population data and whatsoever by determining the total of DF/DHF/DSS cases with the number of population per village each year. 
Based on the local spatial autocorrelation statistics (LSAS) method, the hotspot of DF/DHF/DSS incidence analysis map was generated for 2001 and 2007 years by using the spatial statistics tools in the ArcGIS 10 ArcToolbox software. Moreover, the kernel-density transformation is one of the most useful in applied GIS analysis. First, it provides a very good way of visualizing a point pattern to detect hotspots. Second, since it produces a map of estimates of the local intensity of any spatial process, it is also a useful way to check whether or not that process is first-order stationary. A first-order stationary process should show only local variations from the average intensity rather than marked trends across the study region. Third, it provides a good way of linking point objects to other geographic data [59]. KDE method is used to obtain spatially smooth estimates of the local intensity of points of DF/DHF/DSS cases by village locations in years 2001 and 2007 (Figure 6). The function gives the value of $\hat{\lambda}_{\mathrm{P}}$ for a specified point pattern, evaluated over a grid of locations that span a particular polygon. The width of the kernel is specified by average distance of flying dengue mosquito of 2 kilometres. One useful display is a raster image [60]. The mean center of disease was shows cluster pattern in the center of the province, Bang Khla district, and also shows how the mean center locations of disease changed in space and time by movement of location 1 to location 5 (May to September) in years 2001 and 2007. The spatial statistics are used to summarize the description of a set of locations, followed by measures indicating the directional biases of a set of points. The DF/DHF/DSS risk map obtained from the research is able to support public health officers in space and time so as to control and predict dengue spread over an extension area. Moreover, the risk map can be beneficial for public warning and awareness. Public health officers may employ the model to control DF/DHF/DSS distribution and hotspots through factors mentioned above. Not only it is applicable in epidemics, but this model is general and can also be applied in other application fields such as outbreak of other diseases during natural disasters.

\section{ACKNOWLEDGEMENTS}

I would like to express my sincere gratitude to School of Information and Communication Technology (ICT), University of Phayao, Thailand for providing financial support to this study. Special thanks to Chachoengsao Provincial Public Health Office, Department of Administration, Department of Meteorology, Thailand for data and information.

\section{REFERENCES}

[1] M. Fakeeh, A. M. Zaki, "Virologic and serologic surveillance for dengue fever in Jeddah, Saudi Arabia, 1991-1999," American Journal of Tropical Medicine and Hygiene, vol.65, pp. 764-767, 2001.
[2] K. Nakhapakorn, N. K. Tripathi, "An information value based analysis of physical and climatic factors affecting dengue fever and dengue hemorrhagic fever incidence," International Journal of Health Geographics, vol.4, no.13, 2005.

[3] M. Derouich, A. Boutayeb, E. H. Twizell, "A model of dengue fever," Biology Engineering, vol.2, no.4, 2003.

[4] D. J. Gubler, "Dengue and dengue hemorrhagic fever," Clinical microbiology reviews, vol.11, pp. 480-496, 1998.

[5] World Health Organization (WHO), "Vector control for malaria and other mosquito-borne diseases," Report of a WHO study group technical report series, Geneva, vol.857, pp. 1-99, 1995.

[6] P. Kittayapong, S. Yoksan, U. Chansang, C. Chansang, "A Bhumiratana, suppression of dengue transmission by application of integrated vector control strategies at sero-positive GIS-Based Foci," American Journal of Tropical Medicine and Hygiene, vol.78, pp. 70-76, 2008.

[7] B. H. B. Vanbenthem, S. O. Vanwambeke, N. Khantikul, C. Burghoorn-Maas, K. Panart, L. Oskam, E. F. Lambin, P. Somboon, "Spatial patterns of and risk factors for seropositivity for dengue infection," American Social of Tropical Medicine and Hygiene, vol.72, pp. 201-208, 2005.

[8] P. Barbazan, S. Yoksan, J. P. Gonzalez, "Dengue hemorrhagic fever epidemiology in Thailand: description and forecasting of epidemics," Microbes and Infection, vol.4, pp. 699-705, 2002.

[9] M. Ali, Y. Wagatsuma, M. Emch, R. F. Breiman, "Use of a geographic information system for defining spatial risk for dengue transmission in Bangladesh: role for Aedes albopictus in an urban outbreak," American Society of Tropical Medicine and Hygiene, vol.69, pp. 634-640, 2003.

[10] P. C. Wu, J. G. Lay, H. R. Guo, C. Y. Lin, S. C. Lung, H. J. Su, "Higher temperature and urbanization affect the spatial patterns of dengue fever transmission in subtropical Taiwan," Science of the total Environment, vol.407, pp. 2224-2233, 2009.

[11] C. Rotela, F. Fouque, M. Lamfri, P. Sabatier, V. Introini, M. Zaidenberg, C. Scavuzzo, "Space-time analysis of the dengue spreading dynamics in the 2004 Tartagel outbreak, Northern Argentina," Acta Tropica, vol.103, pp. 1-13, 2007.

[12] V. Herbreteau, F. Demoraes, W. Khaungaew, J. P. Hugot, J. P. Gonzalez, P. Kittayapong, M. Souris, "Use of Geographic Information Systems and Remote Sensing for assessing environment influence on Leptospirosis incidence, Phrae province, Thailand," International Journal of Geographics, vol.2, pp. 43-49, 2006. 
[13] A. Mondini, F. Chiaravalloti-Neto, "Spatial correlation of incidence of dengue with socioeconomic, demographic and environmental variables in a Brazilian city," Science of the Total Environment, vol.393, pp. 241-248, 2008.

[14] A. C. Yost, "Probabilistic modeling and mapping of plant indicator species in a Northeast Oregon industrial forest, USA," Ecological Indicators, vol.8, pp. 46-56, 2006.

[15] Y. A. Twumasi, E. C. Merem, "GIS applications in land management: The loss of high quality land to development in central Mississippi from 19872002," International Journal of Environmental Research and Public Health, vol.2, pp. 234-244, 2005.

[16] L. Anselin, Spatial statistical modeling in a GIS environment: GIS, Spatial Analysis, and ModelingChapter 5. ESRI Press, California, USA, pp. 93-111, 2005.

[17] United States Department of Agriculture (USDA), West Nile Virus: In equids in the Northeastern United States in 2000. New York, USA, pp. 1-42, 2001.

[18] M. P. Ward, M. Levy, H. L. Thacker, M. Ash, S. L. Norman, G. E. Moore, P. W. Webb, "Investigation of an outbreak of Encephalomyelitis caused by West Nile virus in 136 horses," Journal of American Veterinary Medical Association, vol.225, pp. 75-84, 2004.

[19] R. Harris, Z. Chen, "Giving dimension to point location: urban density profiling using population surface models," Computers, Environment and Urban Systems, vol.29, pp. 115-132, 2005.

[20] C. A. Wittich, Spatial analysis of West Nile virus and predictors of hyperendemicity in the Texas equine industry [Thesis]: Texas A\&M University, 2007.

[21] G. Hay, K. Kypri, P. Whigham, J. Langley, "Potential biases due to geocoding error in spatial analyses of official data," Health \& Place, vol.15, pp. 562-567, 2008.

[22] J. T. Watson, J. C. Roderick, K. Gibbs, W. Paul, "Dead crow reports and location of human West Nile Virus cases, Chicago, 2002," Emerging Infectious Diseases, vol.10, pp. 938-940, 2004.

[23] J. S. Brownstein, H. Rosen, D. Prudy, J. R. Miller, M. Merlino, F. Mostashari, D. Fish, "Spatial analysis of West Nile Virus: rapid risk assessment of an introduced vector-borne zoonosis," Vector Borne and Zoonotic Diseases, vol.2, pp. 101-112, 2002.

[24] E. Liebscher, "Strong convergence of sums of $\alpha$ mixing random variables with applications to density estimation," Stochastic Processes and their Applications, vol.65, pp. 69-80, 1996.
[25] H. T. Wist, M. Dag, H. Rue, "Statistical properties of successive wave heights and successive wave periods," Applied Ocean Research, vol.26, pp. 114$136,2005$.

[26] A. D. Cliff, J. K. Ord, Spatial autocorrelation. Pion London, pp. 178, 1973.

[27] M. F. Goodchild, Spatial autocorrelation. Geo, Norwich, United Kingdom, pp. 56, 1986.

[28] D. A. Griffith, Spatial autocorrelation: A Primer. Research Publication in Geography, Association of American Geographers, Washington D.C., USA, pp. 82, 1987.

[29] T. Warner, M. C. Shank, "Spatial autocorrelation analysis of hyperspectral imagery for feature selection," Remote Sensing Environment, vol.60, pp. 58-70, 1997.

[30] J. Lee, L. K. Marion, "Analysis if spatial autocorrelation of U.S.G.S 1:250,000 digital elevation models," American Society for Photogrammetry and Remote Sensing, pp. 504-513, 1994.

[31] P. Haggett, A. D. Cliff, A. Frey, Locational analysis in human geography 2: Locational methods. John Wiley, New York, pp. 605, 1977.

[32] L. S. Premo, "Local spatial autocorrelation statistics quantify multi-scale patterns in distributional data: an example from the Maya Lowlands," Journal of Archaeological Science, vol.31, pp. 855-866, 2003.

[33] X. Cai, D. Wang, "Spatial autocorrelation of topographic index in catchments," Journal of Hydrology, vol.328, pp. 581-591, 2006.

[34] A. Getis, J. K. Ord, "The analysis of spatial association by use of distance statistics," Geographical Analysis, vol.24, pp. 189-206, 1992.

[35] N. A. C. Cressie, Statistics for spatial data. Wiley, New York, pp.900, 1993.

[36] M. A. Wulder, J. C. White, N. C. Coops, "Using local spatial autocorrelation to compare outputs from a forest growth model," Economical Modeling, vol.209, pp. 264-276, 2007.

[37] B. Flahaut, M. Mouchart, E. S. Martin, I. Thomas, "The local spatial autocorrelation and kernel method for identifying black zones a comparative approach," Accident Analysis and Prevention, vol.35, pp. 9911004, 2002.

[38] L. Anselin, Spatial econometrics: Methods and Models, Kluwer Academic Publishers, Dordrecht, The Netherlands, pp. 284, 1988.

[39] L. Anselin, S. Rey, "Review-Introduction to the special issue on spatial econometrics," International Regional Science, vol.20, pp. 1-7, 1997. 
[40] R. K. Pace, R. Barry, C. F. Sirmans, "Spatial statistics and real estate," Journal of Real Estate Finance, vol.17, pp. 5-13, 1998.

[41] J. L. Ping, C. J. Green, R. E. Zartman, K. F. Bronson, "Exploring spatial dependence of cotton yield using global and local autocorrelation statistics," Field Crops Research, vol.89, pp. 219236, 2004.

[42] A. K. Yeshiwondim, S. Gopal, A. T. Hailemariam, D. O. Dengela, H. P. Patel, "Spatial analysis of malaria incidence at the village level in areas with unstable transmission in Ethiopia," International Journal of Health Geographics, vol.8, pp. 1-11, 2009.

[43] D. J. Gubler, Dengue and dengue hemorrhagic fever; its history and resurgence as a global public health problem. In Dengue and Dengue Hemorrhagic Fever bulletin, pp. 22, 1997.

[44] J. H. Jetten, D. A. Focks, "Changes in the distribution of dengue transmission under climate warming scenarios," American Journal of Tropical Medicine and Hygiene, vol.57, pp. 285-297, 1997.

[45] World Health Organization (WHO). Dengue hemorrhagic fever: Diagnosis, treatment, prevention and control, 2nd ed.; Geneva, 1997.

[46] J. L. Meza, "Empirical Bayes estimation smoothing of relative risks in disease mapping," Journal of Statistical Planning and Inference, vol.112, pp. 4362,2002

[47] R. J. Marshall, "Mapping disease and mortality rates using empirical Bayes estimators," Journal of the Royal Statistical Society: Series C (Applied Statistics). vol.40, pp. 283-94, 1991.

[48] J. K. Ord, A. Getis, "Local spatial autocorrelations statistics: distributional issues and application," Geographical Analysis, vol.27, pp. 286-306, 1995.

[49] S. Hinman, J. K. Blackburn, A. Curtis, "Spatial and temporal structure of typhoid outbreaks in Washington D.C., 1906-1909: evaluating local clustering with the $G_{i}^{*}$ statistic," International Journal of Health Geographics, vol.5, pp. 1-13, 2006.

[50] A. Getis, A. C. Morrison, K. Gray, T. W. Scott, "Characteristics of the spatial pattern of the dengue vector, Aedes aegypti, in Iquitos, Peru," American Journal of Tropical Medicine and Hygiene, vol.69, pp. 494-505, 2003.

[51] J. Wu, J. Wang, B. Meng, G. Chen, L. Pang, X. Song, K. Zhang, T. Zhang, X. Zhang, "Exploratory spatial data analysis for the identification of risk factors to birth defects," BMC Public Health, vol.4, pp. 1-23, 2004.

[52] F. I. MacKellar, In The Cambridge World History of Human Disease; Kiple, K.F., Ed.; Early mortality data: sources and difficulties of interpretation, Cambride University, pp. 209-213, 1993.

[53] M. P. Ward, T. E. Carpenter, "Techniques for analysis of disease clustering in space and in time in veterinary epidemiology," Preventive Veterinary Medicine, vol.45, pp. 257-284, 2000.

[54] D. W. S. Wong, J. Lee, Point Pattern Descriptors: Statistical Analysis of Geographic Information with ArcView GIS and ArcGIS. John Wiley \& Sons, Inc., Hoboken, New Jersey, USA, pp. 189-192, 2005.

[55] S. Hales, P. Weinstein, A. Woodward, "Dengue fever epidemics in the South Pacific: by El Nino Southern Oscillation," Lancet, vol.348, pp. 16641665, 1996.

[56] J. Keating, "An investigation into the cyclical incidence of dengue fever," Social Science Medicine, vol.53, pp. 1587-1597, 2001.

[57] D. Guha-Sapir, B. Schimmer, "Review, Dengue fever: new paradigms for a changing epidemiology," Emerging Themes in Epidemiology, vol.2, no.1, 2005.

[58] K. Nakhapakorn, S. Jirakajohnkool, "Temporal and Spatial Autocorrelation Statistics of Dengue Fever," Dengue Bulletin, vol.30, pp. 177-183, 2006.

[59] D. O’Sullivan, D. Unwin, D. Point Pattern Analysis: Geographic information Analysis. John Wiley \& Sons, Inc., Hoboken, New Jersey, USA, pp. 81-88, 2003.

[60] S. Fotherringham, P. Rogerson, Spatial analysis and GIS. Department of Geography, SUNY at Buffalo, 1994.

Dr. Phaisarn Jeefoo is a lecturer in Geographic Information Science field of study at the School of Information and Communication Technology (ICT), University of Phayao, Thailand. In teaching, I have been focusing on applying Remote Sensing and Geographic Information System (RS\&GIS) techniques and disease disaster approaches in Computer Programming Educations. In research, his current interests include Application of Remote Sensing and GIS in Health and Environment, GIS Programming, Open Source Software, Database Management, Digital Image Processing for environmental disaster and so forth. 